\title{
On Back Translation of Sinological Works Written in English*
}

\author{
Hongwei Ye \\ School of Foreign Languages, Shanghai University of Engineering Science, Shanghai, China
}

\begin{abstract}
The Chinese translation of sinological works is a unique translation phenomenon, because although these sinological works are written in English, they reflect the social life of China and are full of Chinese cultural elements. Based on the studying of the textual features sinological literature and the current situation of sino logyical translation in China, this paper analyzes the back translation techniques commonly used in the translation of sinological works.
\end{abstract}

Index Terms — sinological works, back translation, cultural elements

\section{INTRODUCTION}

During the past two decades, a large number of sinological works written by western sinologists in English have been translated into Chinese. Although written in English, these sinological works are mainly about Chinese language, society, history or customs, involving many Chinese cultural elments. In the translation of such works, cultural restoration of these elements is often required, which is also known as back translation. This unique translation phenomenon has attracted extensive attention and heated discussion among translators and translation theorists.

\section{BACK TRANSLATION}

As a special translation phenomenon, back translation has been discussed and defined in translation academia for a long time, but its importance in translation practice and its position in translation theory research have not been fully recognized.Ge (1980) defined back translation as the translation of a text previously translated from language A into language $\mathrm{B}$ back to language $\mathrm{A}$. He added that the advantages and disadvantages of this method of translation, as a method of teaching, hve not been fully discussed. However, it is common in the actual translation today, though often unconsciously. Shuttleworth and Cowie (2004)) defined back translation as "a process in which a text which has been translated into a given language is retranslated into SL. The procedure of back translation has been used for various different purposes." (p.14) In western academic circles, back translation is more often used as a method of translation teaching and language comparison to study the structural and conceptual differences between the source language and the target language. Spalatin (1967) applied back translation into contrastive linguistics and pointed out that back translation is a translation technique used to compare specific syntactic features, morphological features or lexical features in two or more languages

In China, with more and more attention paid to back translation practice and related theories in recent years, its definition is constantly revised and improved. In the early days, some Chinese scholars had a relatively narrow understanding of back translatation. Feng and $\mathrm{Li}$ (2001), for example, believed that "back translation is the most direct and reliable means to check mistranslation", and clearly pointed out that " back translation can be used to check the translated text, and its efficacy is unmatched by other methods". He (2002) believed that "the so-called" back translation "means to translate the target text again and turn the translation back into the original text"(p.46). Chen and Pan (2008) pointed out that "back translation" refers to the translation activity of translating the linguistic and cultural materials from the target language into the source language by tracing the internal linguistic and cultural connections. This definition does not regard back translation as a simple process of returning to the original text, but emphasizes the "internal linguistic and cultural relationship" between the source language text and the target language text, and examines the two from the perspective of "intertextuality". In this way, the concept of back translation has been greatly deepened and extended.

\section{TEXTLESS BACK TRANSLATION}

With the increasingly frequent exchanges and interactions between China and western countries, it is inevitable that some Chinese cultural elements are integrated into foreign culture and written into the their literary works, making some English texts to be translated mixed with Chinese culture, among which overseas English sinological works are

\footnotetext{
* This article is one of the phased research results of "Foreign language and Literature First-Tier Discipline Construction Project(外国语语言文学 一级学科建设项目）" of Shanghai University of Engineering Science.
} 
the representatives. When this kind of Chinese cultural works written in English are translated into Chinese, it will involve "textless backtranslation", a concept first put forward by Wang Hongyin. Wang (2004) began to pay attention to this unique translation phenomenon in 2004 by quoting a paragraph from "The analects of Confucius-A philosophical translation" by Ames T. Roger and Henry Rosemont (2003): In recent years, the "reciprocating translation" between Chinese and English in Chinese traditional classics seems to be a noteworthy phenomenon. The so-called "reciprocating translation" here refers to a situation in which a classic is translated into English and is accompanied by a large number of notes provided by the translator, which involves not only certain specific historical knowledge and cultural backgrounds but also the author's understanding and interpretation of the classics, and the translation of the classics themselves, such as explaining why this paragraph or this sentence should be translated in this way, and so on. If this kind of works are translated into Chinese publication, they have almost gone through the reciprocating cycle of "Chinese $\rightarrow$ English $\rightarrow$ Chinese", which can be understood as the "reciprocating translation" between the two languages in a broader sense. (p.325) In 2009, he first came up with the concept of "rootless back translation".He pointed that Moment in Peking takes Chinese culture and life in old Beijing as the theme and content, but its original text is written in English. This kind of back translation to Chinese is only the return of culture, not the return of language, so it is called "rootless back translation", that is, there is no back translation based on the original text. (Wang, 2009) After years of academic research and observation, he revised the concept in 2015. He claimed that the expression "rootless back translation" is not quite accurate, and would rather name it "textless back translation". The so-called "textless back translation" is at best a back translation without the basis of the text, but there is still a cultural root (here is Chinese culture, not general human culture) as the foundation, rather than a complete lack of cultural roots. Therefore, it is more accurate to call it textless back translation. This revision of the concept is not literal or superficial, but essential and critical. (Wang, 2015)

\section{Translation and Publication of English SinOlogy Works in ChinA}

Sinology has a long history as a unique culture born, grown and developed after the collision, exchange and integration of Chinese culture and heterogeneous cultures. With the further development of reform and opening up, the unprecedented activity of cultural exchanges with foreign countries and the constant expansion of academic horizons, domestic scholars are attaching more and more importance to the research results of overseas sinology, and a large number of literatures related to "sinology" have been translated and introduced to China. The translation and publication of these sinological documents not only provides a large number of first-hand research materials for domestic academia, but also refreshingly benefits domestic scholars with their perspectives, methods and viewpoints on sinology. Since the 1980s, with the increasing translation and introduction of overseas sinological literatures in China, some publishing houses began to cooperate with some domestic sinology research institutions to continuously translate and publish sinological works from all over the world, forming a number of relatively complete and independent series. For example, the "Overseas Sinology Series" published by Shanghai Guji Press has produced more than 20 kinds of overseas sinological classics, which have been well received by the academic circles at home and abroad. The selected works in the "Overseas Sinology Series" were all written by famous sinologists from the United States, Japan, France, Britain, Canada and Russia, covering Chinese philosophy, history, literature, religion, folk customs, economy, science and technology and many other aspects. Of all the sinological series, the largest and longest is the "Overseas Chinese Studies Series" launched by Jiangsu People's Press, which has gone through a course of nearly 30 years since 1988. More than 150 kinds of overseas sinological works have been translated and published, including the representative works of many famous overseas scholars, such as John King Fairbank, Prasenjit Duara, Benjamin I.Schwartz, Stephen Oven, David Faure, Jonathan D. Spence and so on, and enjoy a high reputation in the academic and publishing circles. The Chinese Characteristics, for example, was written by American missionary Arthur Smith. He has lived in China for more than 50 years, and commented on the characteristics of the Chinese people from the standpoint of western civilization and Christianity, which can still arouse the interest of many Chinese people today. Since the 1990s, nearly ten publishing houses, such as Xueyuan Press, Guangming Daily Press, Jinghua Press, Shanghai Xuelin Press, Shuhai Press, New World Press, China Book Company and Shanghai Sanlian Bookstore, have translated and published the Chinese version of this book. (Ye, 2015)

With the joint efforts of young and old scholars, remarkable achievements have been made in the translation and research of foreign Chinese studies. The translation and publication of a large number of foreign classics of Chinese studies have effectively promoted the development of domestic philosophy, historiography, literature, the history of sino-foreign relations, the history of border regional culture, and so on. These works not only provide a large number of first-hand research materials for domestic scholars, but also enlighten domestic scholars in methodology (Zhang, 1992). The introduction of western sinological literature has greatly promoted the in-depth development of sinology studies in China. In the meanwhile, many scholars and translators find it a unique translation phenomenon after reading or translating sinological works involving Chinese cultural content, and discussed the problems in combination in them with specific translation cases. The main problems in the translation of sinological works include: inaccurate back-translation, lack of unified translation norms and lack of qualified translators.Zhang (2005) discussed the back translation of Building Culture in Early Qin Yangzhou written by Tobie Meyer-Fong. He believed that "faithfulness and truthfulness" are the basic norms of academic translation. Whether the translation of academic works can comply with 
this criterion is an important basis for judging whether they are excellent translated works. He pointed out that the transtation of Building Culture in Early Qin Yangzhou had some common problems in the back translation of names, places, titles and quotes from Chinese classics. He analyzed the reasons behind these problems and believed that in addition to the translator's own attitude, the deeper reason might also be the current academic atmosphere and academic evaluation system.Academic translation is a very hard work, and the current academic evaluation system does not put the translation of academic works in an important position. Coupled with the short publication cycle, tight time and other external factors, many of the works have been published without repeated revisions and careful proofreading.Zhang (2007) claimed that the translation of sinological works has problems in terms of vocabulary, syntax and knowledge background. After being translated back into Chinese, the polishing of words and the rhythm of writing are also difficult problems for translators. He sumed up the skills used in the translation of the English version Social thoughts of the Late Qing Dynasty, analyzed the challenges the translator confronts with and explored the theory and possible means in handlingsuch tasks. Wei(2013) took the translation of China's Megatrends: The 8 Pillars of a New Society as an example and analysed the strategies of back translation and pointed out that translation should be faithful to both the original text and common sense. He believed that due to the particularity of China-themed works, Chinese translators should assume more responsibilities in the process of translation. The translators should not only faithfully reflect the author's views and accurately transfer the Chinese elements in the translated works, but also give full play to the translator's subjective initiative, review and proofread the facts and details related to China and Chinese culture, correct the mistakes and even give feedback to the author in time. This is not only the translator's right, but also the translator's responsibility, which is helpful to improve the overall quality of social science works related to China.

\section{PRinciples AND TeChNiQues of BACK TRANSlation of ENGLish SinOlogical Works}

There are many reasons for the problems in the translation of sinological works. However, the main reason is undoubtedly the translator's insufficient understanding of the particularity and complexity of back translation and the lack of corresponding coping strategies. Compared with the general English-Chinese translation, the translation of sinological works has its particularity. Translators need to fully analyze and consider the specific text and adopt corresponding translation strategies in order to present high-quality translations to readers. To achieve this goal, the following back translation strategies and techniques can to be taken into consideration.

\section{A. Meeting Readers' Expectation}

For a long time, traditional translation theories have ignored the role of readers. Only after the theory of reception aesthetics was introduced into translation studies, did the factor of readers begin to be formally mentioned on the agenda of translation studies, which is also favored by more and more translation researchers.In the process of translation, the translator must consider the existence of the readers and, according to the expectation and acceptance level of the readers, pursue the blending of the target text and the target text reader's vision as much as possible. It is undeniable that readers have different expectations for the same work due to their different ages, educational levels, cultural backgrounds and aesthetic orientations. However, since the sinological works deal with Chinese themes, the readers' expectations for the translation are relatively more consistent. In the eyes of readers, the main themes of sinology are undoubtedly Chinese society, history and culture,so Therefore, its Chinese expression should be smooth, fluent and authentic. In addition, the translation should conform to the norms of Chinese expression and should not have an obvious style of translationese.

Example: Generally speaking, no Chinese will leave his home to seek his fortune at a distance, unless he is in someway driven to do so. His ideal of life is to be "Fixed like a plant on his peculiar spot, to draw nutrition, propagate, and rot." Generally speaking, no Chinese leaves his home not intending to return. His hope is always to comeback rich, to die and be buried where his ancestors are buried.

Version 1: 总的来说, 除非被逼无奈, 中国人不愿意背井离乡, 到远方去谋生, 中国人的理想生活是

“像植物一样根植土壤, 生长结果, 然后腐烂。”总的来说中国人没有离家之后不打算再回去的, 他们

的希望永远是衣锦还乡, 寿终正寝, 最后被葬入祖坟。

Version 2: 普遍来说, 没有一个中国人愿意背井离乡, 到远方寻找幸福, 除非他们是逼迫上路的。他们

理想的生活是“像树一样扎下根, 滋养, 繁殖、腐烂。”总体说, 中国人没有离家不归的, 他总希望发

财回来, 死在家里, 葬入祖坟。

The Chinese language boasts very rich "four-character" phrases, most of which have been repeatedly condensed and gradually formed. Although the four-character phrases are short, they often have profound meaning and strong expressive force. Proper use of them can improve the quality of the translation and make the translation look more authentic and natural. In particular, since the original work itself is to introduce the characteristics of the Chinese people, readers will have expectations for natural and fluent Chinese expression.In both Version 1 and Version 2, the translators translate “ leave his home” into “背井离乡”, and in Version 1, “come back rich", and "to die and be buried” are translated as "衣锦还乡" and "寿终正寝"respectively.These are typical four-character structure in Chinese, which not only convey the content of the original text, but also easily arouse the resonance of Chinese readers and cater to their the aesthetic expectations. 


\section{B. Being Flexible in Back Translation}

For a long time, back translation has been simply regarded as a textual research activity tracing back to its roots, and the understanding and definition of "back translation" is relatively narrow. The Chinese cultural elements in sinological works are often translated or pharaphrased by the author according to Chinese, so it is necessary to adapt them flexibly according to the circumstances when they are translated back into Chinese. It is generally believed that back translation is the process from the original text to the target text and then back to the original text. However, in actual translation practice, there will be such a situation, that is, the quote in the English text is not necessarily a faithful translation of Chinese, instead, it may be interpretation, description or rewriting. However, the process of these explanations and descriptions being translated back into Chinese is also a kind of back translation.

Example: On the river island

The ospreys are echoing us

Where is the pure-hearted girl

To be our princess?

Version: 在河中的沙洲上,

白鹭与我们声唱音随。

心地纯洁的姑娘, 你在哪里?

你将作我们的王妃。

Note: 关关睢鸠, 在河之洲,

窈宠淑女, 君子好逮。

It is generally believed that the best way to translate such quotations from Chinese is to find the original Chinese text. which is also what we traditionally call the back translation. This is a poem cited in a sinological work. Since it is an ancient Chinese poem, the wording in the poem is ancient and elegant, and the average young Chinese reader may not be able to understand it, let alone foreigners. As a result, Tang(1991) argued that it was impossible for the young American to read such ancient Chinese poem as "关关雎鸠,在河之洲”. In fact, he was reading a translated ancient Chinese poem in English.According to the principle of equivalence, the information expressed in the original English text about this ancient Chinese poem-that is, their interpretation and understanding of the poem-should be reflected in the translation. Otherwise, wouldn't it be ridiculous for a contemporary foreign youth who doesn't understand Chinese to read "关关雎鸠,在河之洲?"Of course, in processing, after translating the poem according to the original English text, a note can be added to list the full text of the original poem."Translation Notes" is an important part of the translated works, through which the translator can help readers better understand the original text. Therefore, it is also a commonly used translation skill in the translation of sinological works.

Therefore, in the practice of back translation, flexible strategies should be adopted according to different situations. The translator should pay attention to the comprehensive consideration of the Chinese classical quotations in foreign language texts, conduct multi-dimensional analysis of the specific variables such as syntax, semantics, logic, culture and communicative context, and adopt the processing method suitable for the specific context.(Liu, 2018)

\section{Omitting Explanatory Text}

The content of English sinology literature is about Chinese culture, but its readers are mainly British and American people, some of whom are not familiar with Chinese cultural elements. Therefore, in the process of writing and Chinese-English translation, the author will inevitably add explanatory text to some words and sentences involving cultural elements so as to help English and American readers better understand the original text. When those works are translated back into Chinese, the target readers become Chinese readers familiar with the Chinese language and culture. If all these explanatory languages are translated into Chinese, the translated text will become redundant and even cause confusion.

Example: There are three regular degrees conferred upon successful candidates at the government examinations. The lowest gives the title of "Hsiu Tsai," or "Budding Talent;" the second of "Chu Jên," or Promoted Man;" and the third, that of "Chin Shih," or "Entered Scholar."

Version 1: 参加科举考试的考生成功通过考试后, 会根据所参加考试的级别分别授予三种常见学位, 最低的 叫“秀才”，第二级叫“举人”，第三级叫“进士”。

The author introduces the imperial examination system in ancient China in English. In describing three different degrees, the author uses three transliteration words "Hsiu Tsai", "Chu Jên" and "Chin Shih" to represent them. The average English readers do not understand the meaning of these transliteration words, so in order to help English readers better understand them, the author adds an explaination after each transliteration,ie "Budding Talent" "Promoted Man" and "Entered Scholar". However, for Chinese readers, explanatory appositions are obviously superfluous, unnecessary and should be omitted in translation. It can be seen that these explanatory texts, which are compensated for to help the original readers understand the meaning of the text, have their value and necessity in the original language text. But if it is still retained when translated back into Chinese, it will be inexplicable to Chinese readers familiar with Chinese culture, because in their view, these are just common sense. 


\section{CONCLUSION}

The translation and introduction of overseas sinology research results in China has played an indispensable role in promoting the academic prosperity and cultural exchange between China and the West. Sinology translation is a bridge between sinology scholars in China and abroad, and has great significance in inheriting civilization and constructing a harmonious world.(Wan,2012) In the past, the translation of sinological works has not received enough attention from the academic circle. However, at present, many studies have not only analyzed translation errors and translation skills in the translated works, but also began to analyze the translation of sinological works as a whole. As a special translation phenomenon, back translation of sinological works enriches the forms of translation and enables us to better understand the complexity and diversity of translation activities. This paper analyzed the characteristics of the back translation of sinological works and made a preliminary discussion on the back translation strategies in the hope of enlightening more scholars to carry out more in-depth research in this field and constantly improving the translation quality of sinological works.

\section{REFERENCES}

[1] Ames, T.R and H. Rosemont. (2003). The Analects of Confucius-A Philosophical Translation. Beijing: Beijing: China Social Science Press. 325-326.

[2] Chen, Z.J.and H.L. Pan. (2008). Back translation: the intersection of Cultural Globalization and Localization. Shanghai Journal of Translators. 3,58-59.

[3] Feng, Q.H and M. Li. (2001). On Stylistic Translation. Shanghai: Shanghai foreign language education press.434-436.

[4] Ge, Chuangui. (1980). On Chinese English Translation. Chinese Translators Journal, 3, 2-5.

[5] He, X. (2002). Types, characteristics and application methods of back translation. China science and technology translation. 4, 46-47.

[6] Liu, A. H. (2018). Back-translation of Chinese Classics: A Multi-contextual Scheme. Foreign Language Research.4, 116-118.

[7] Shuttleworth, M and M.Cowie. (2004). Dictionary of Translation Studies. Shanghai: Shanghai Foreign Language Education Press.32-56.

[8] Spalatin, L. (1967). “Contrastive Methods”. Studia Romanica et Anglica Zagrabiensia 23,29 -48.

[9] Wang, H.Y. (2004). On Background Variables of Translation Criticism in Literature. Chinese Translators Journal, $2,33-38$.

[10] Tang, Z.Q. (1991). The Other Side of the Turkish Tapestry -- on the principle of equivalence in translation and its application in practice. Chinese Translators Journal, 3, 21-25.

[11] Wang, H.Y. (2009). An introduction to Literary Translation criticism: from Literary criticism to Translation Teaching. Beijing: China Renmin University Press.326-327.

[12] Wang, H.Y. (2015). Text-less Back translation Reviewed and Reconsidered. Shanghai Journal of Translators, 3, 1-9.

[13] Wei, P. (2013). "Faithfulness principle" in the Back translation of Chinese Elements in Sinological works. Shangdong Foreign Language Teaching Journal. 1,105-107.

[14] Ye, H.W. (2015). Research on the Ttranslation and Publication of Sinological Literature in China in the Past 30 Years. Publish Research, 5, 62-63.

[15] Zhang, N. (2007). On the Back translation Principles and Techniques of the English Sinological Publications. Journal of Hubei University (Philosophy and Social Science).4, 92-93.

[16] Zhang, Y.Q. (2005). Ancient Literature: Translation and Back translation-Exemplified by the Chinese Back translation of Building Culture in Early Qing Yangzhou. Joural of Nanjing University.3, 134-136.

[17] Wan, X. M. (2012). On the Translation of Sinology. Journal of School of Chinese Language and Culture Nan jing Normal University. 1, 84-88.

[18] Zhang, X.P. (1992). A Review of Translation and Research on overseas Chinese Studies in China in recent years. Journal of the National Library of China.1, 110-113.

Hongwei Ye was born in Jiangxi, China, in 1978. He received his MA degree in English language and literature from Shanghai University, China, in 2006. He is currently an associate professor at the School of Foreign languages, Shanghai University of Engineering Science. He is a member of Translators Association of China and a member of Shanghai Science and Technology Translation Society. 